\title{
Um estudo sobre a fidelização de clientes no segmento de varejo de moda
}

\section{A study on customer loyalty in the fashion retail segment}

PANCHERA, Lucas

Instituto Federal de Santa Catarina - IFSC | luucaspan@gmail.com

OLIVEIRA, Aline Hilsendeger Pereira de

Instituto Federal de Santa Catarina - IFSC | alinep@ifsc.edu.br

\begin{abstract}
Resumo
Este artigo tem por objetivo expor métodos efetivos para fidelização de clientes em empresas de varejo de moda. Especificamente, abordouse o conceito de marketing de relacionamento e foi feito um levantamento das ferramentas existentes, selecionando a mais adequada para se aplicar em um varejo de moda. Foi realizada uma pesquisa qualitativa, exploratória e elaborou-se um estudo de caso dentro de uma empresa da área afim para analisar a taxa de fidelidade dos clientes.
\end{abstract}

Palavras chave: Fidelização. Marketing de relacionamento. Varejo. Moda.

\section{Abstract}

This paper aims to identify effective methods for customer loyalty in fashion retail companies. Specifically, we approach the concept of relationship marketing and existing implementation tools, selecting the most suitable for the fashion retail market. The research conducted is qualitative and exploratory, with a case study performed within a company in order to analyze the clients' frequency rate.

Keywords: Loyalty. Relationship marketing. Retail. Fashion. 


\section{INTRODUC̣ÃO}

Com o aumento da competitividade do mercado e da concorrência, há uma infinidade de produtos e serviços à escolha do consumidor. Por isso, tornase essencial a criação de um diferencial para aproximar ainda mais os clientes com os produtos, com a marca ou até mesmo da empresa e fidelizá-los.

Os clientes passaram a ser considerados como prioridade pelas organizações por serem cruciais para sobrevivência de uma empresa. Nesse contexto, a utilização de métodos de fidelização de clientes se tornou indispensáveis para qualquer empresa que busque êxito nos negócios.

Neste artigo, são apresentadas algumas técnicas e ferramentas de marketing para fidelização de clientes. Utilizam-se um conjunto de estratégias adotadas pelas organizações para incentivar, influenciar e fidelizar clientes. Assim, o questionamento que se faz no presente artigo é: "Quais ferramentas de fidelização são mais efetivas para aplicar no segmento de varejo de moda?"

Partindo dessa problemática, objetivou-se selecionar as ferramentas de gerenciamento de relacionamento de clientes mais efetivas para aplicar em uma empresa de varejo de moda. Especificamente, buscou-se apropriar do conceito de marketing de relacionamento no varejo de moda, após esse estudo foi realizado um levantamento de quais as ferramentas mais utilizadas como estratégia de fidelização de clientes e, por fim, aplicou-se um estudo de caso em um varejo de moda.

Realizou-se uma pesquisa bibliográfica em livros e periódicos científicos que tratam sobre o objeto de estudo, o marketing de relacionamento. $O$ estudo de caso foi aplicado em uma empresa de varejo de moda localizada na cidade de Meleiro-SC, sendo os dados tratados qualitativamente sob o referencial teórico estudado.

Este artigo se justifica pela importância do relacionamento com os clientes para uma empresa. A sobrevivência de uma marca no mercado cada vez mais competitivo vem da fidelização de sua clientela. Um atendimento satisfatório que supere as expectativas do consumidor é muito importante, a utilização deste artigo poderá aperfeiçoar a relação com os clientes, criando valor para estes, fidelizando-os e, porventura, aumentar a lucratividade e vendas da empresa.

Com as estratégias de diferenciação, as empresas oferecem um maior valor agregado em produtos e/ou serviços que as diferenciam das demais, proporcionando maior satisfação aos consumidores dentro da constante 
demanda do mercado. Nesse caso, além de oferecer de produtos ou serviços, proporcionar experiências e benefícios que atraiam o consumidor, com o propósito de estabelecer fidelidade com a marca empresarial.

\section{O MARKETING DE RELACIONAMENTO DO VAREJO DE MODA}

Descobrir e interpretar os desejos dos consumidores é um processo contínuo, o qual se desenvolve desde a promoção, a distribuição e também no pós-venda. Neste ciclo, pode-se persuadir mais clientes a fazerem uso contínuo de determinados serviços e produtos. Para tanto, as estratégias de marketing vêm evoluindo no sentido de maior aproximação e interação com o consumidor.

Conforme Siqueira (2005), partindo de eventos e situações de negócios, veio a ideia de nutrir o relacionamento da empresa com o cliente. A ideia ganhou força nos anos 90 e diversos fatores como a globalização e as inovações tecnológicas, por exemplo, fizeram com que as organizações e empresas do varejo procurassem maneiras de não apenas obter vantagens competitivas nessa relação com o cliente, mas também, conservá-las.

De acordo com Czinkota e Montingelli Junior (2001), o marketing aborda a identificação das necessidades do cliente e o desenvolvimento de produtos que correspondam às suas expectativas. Kotler (2000, p. 25) relata em sua obra que "normalmente, o marketing é visto como a tarefa de criar, promover e fornecer bens e serviços a clientes, sejam pessoas físicas ou jurídicas". Dessa forma, o papel dele é levar produtos e serviços com os quais o consumidor se identifique, para tanto é necessário conhecer suas necessidades e desejos. Para tal objetivo, este utiliza estratégias para se aproximar dos clientes, como o marketing de relacionamento.

Para Baker (2005, p. 27) o marketing de relacionamento:

[...] desenvolveu-se em contextos de marketing industrial e de serviços como uma reação contra as limitações do marketing tradicional (transacional). Inicialmente desprezado por fabricantes interessados em mercados de massa, as mudanças no clima competitivo no final da década de 1980 e início da de 1990 alimentaram o interesse no marketing de relacionamento em mercados de consumo de massa.

Para Pinho (2008, p. 23), o marketing industrial (MI) tem esse nome por ser utilizado no mercado industrial com clientes organizacionais. Por se tratar de $\mathrm{Ml}$, o interesse é o mercado de massa cujo objetivo são as vendas em grandes volumes, para isso os produtos precisam ser comoditizados, ou seja, padronizados. Engel, Búrigo e Pereira (2015), dizem que o marketing de 
relacionamento (MR) é uma melhoria do tradicional marketing de massa, e, se voltar à essência do marketing, observar-se-á que o mesmo busca compreender não só o que o consumidor quer, mas também o que ele deseja. O querer está relacionado à satisfação de uma necessidade física ou situação de privação, como a fome, por exemplo. $O$ desejar se refere à satisfação de uma necessidade moldada por uma cultura, ou seja, é uma necessidade mais sofisticada (KOTLER; ARMSTRONG, 2015).

Assim, as mudanças na orientação das estratégias de marketing segundo Coltro (2002, p. 2), se referem ao final da Era da Qualidade entre os anos de 1970 e 1989, na qual as empresas buscavam a satisfação dos clientes por meio da melhoria constante dos processos da empresa, para dar espaço à Era da Competitividade nos anos 1990. Nesta década, a principal característica é a busca incessante pela sobrevivência das empresas em uma economia que se encontra cada dia mais globalizada. Nesse novo cenário, pós 1990, no qual o varejo teve um expressivo aumento e representatividade econômica que o marketing de relacionamento vem contribuir como uma ferramenta extremamente efetiva para a permanência das empresas em um mercado tão competitivo (BARKI; BOTELHO; PARENTE, 2013).

Este resgate histórico sobre a evolução dos objetivos do marketing se justifica necessário para a compreensão do como se evoluiu para a importância do relacionamento (Figura 1).

Figura 1 - Linha do tempo da evolução do conceito do marketing.

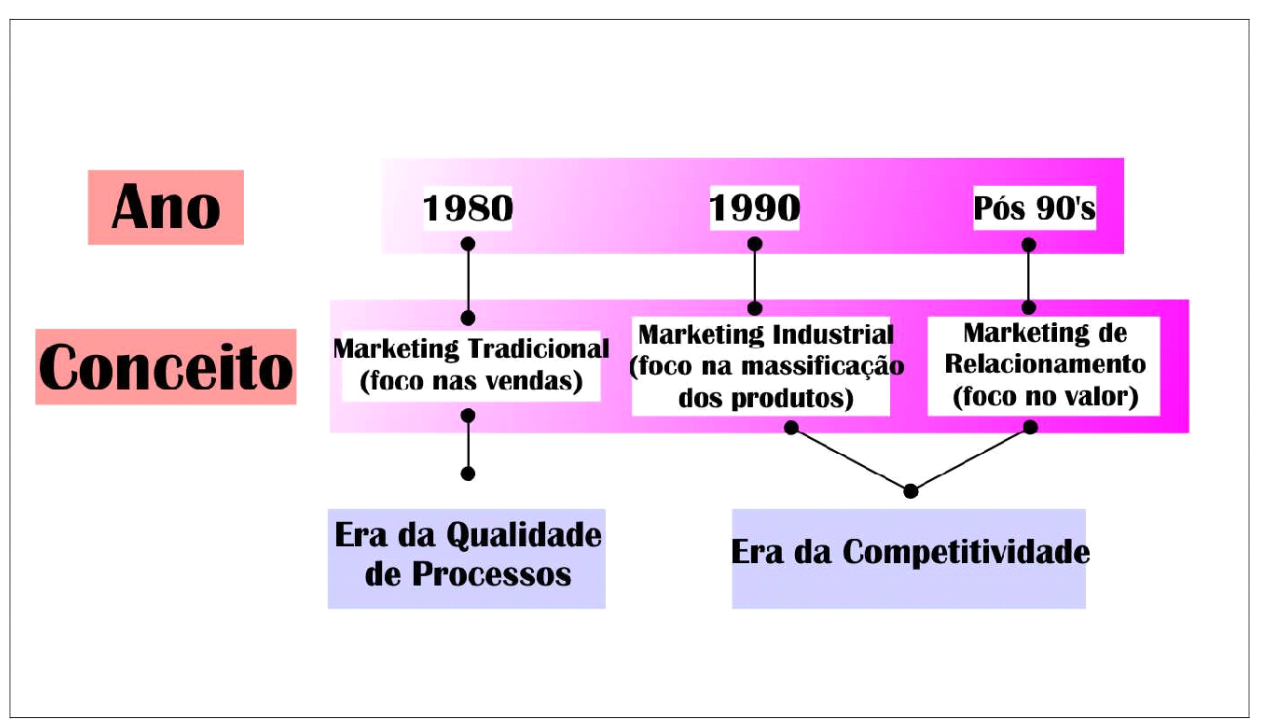

Fonte: elaborado pelos autores a partir do referencial teórico.

Segundo Gordon e Pinheiro (2001, p. 16) o marketing de relacionamento (MR) pode ser conceituado como "o processo contínuo de criação e compartilhamento de valores com os clientes que a empresa escolhe para atender". 
Para Kotler (2005, p. 49) "o marketing de relacionamento é a chave para produzir um elevado patrimônio de cliente". Isso significa dizer que manter uma relação com o cliente que vá além do simples ato da venda, cria um elo entre cliente e empresa. A ideia produz uma relação de troca, na qual o cliente obtém vantagens por estar fidelizado com a sua empresa/marca, e o empresário dispõe de uma ampla divulgação para o seu patrimônio por parte deste cliente já fidelizado, fazendo que não apenas quem vende obtenha benefícios, mas também, quem compra.

Os autores Engel, Búrigo e Pereira (2015) percebem que apesar de óbvios os ganhos de firmar relacionamentos duradouros, o MR ainda hoje é um desafio e não é aplicado de forma adequada. Desta forma, vários gestores de marketing, empresários e executivos comerciais resistem em praticá-lo por crerem que as práticas mercadológicas tradicionais, principalmente a propaganda e promoções, já são suficientes para satisfazer os clientes.

O MR é fundamental em qualquer tipo de empresa, novarejo de moda não seria diferente. Criar vínculos com o cliente através de estratégias de marketing pode ser uma saída interessante, até porque, por mais que pareça óbvia a importância do marketing em uma empresa, muitos ignoram seus benefícios e acabam defasados, perdendo clientes para a ampla concorrência. Segundo Braga (2014), dados mostram que uma empresa possui uma perda anual de clientes de $20 \%$. Isso indica que algo necessita ser feito para interromper esta significativa perda, e é aqui que o marketing de relacionamento entra e se torna uma alternativa praticável para isso.

\section{ESTRATÉGIAS DE FIDELIZAC̄ÃO DE CLIENTES}

Dentre as estratégias de MR, a fidelização dos clientes pode ser realizada por meio de programas de fidelização. Segundo Souza (2009), fidelidade é o nível de predisposição que os clientes têm de permanência em uma empresa e a resistência destes em relação às ofertas vindas da concorrência, ou seja, partindo dessa afirmação, pode-se dizer que quanto mais satisfeitos os clientes ficam, menor será a influência da concorrência sobre ele e, consequentemente, aumenta a fidelização.

Segundo Vieira (2015) a empresa deve pensar de forma estratégica, visando à conquista de alianças duradouras com seus clientes através de produtos qualificados. Kotler e Armstrong (2003, p. 210) falam que o que torna o valor de uma marca forte, real, é o poder que a mesma tem de conquistar a fidelidade e a preferência do consumidor. Ainda citam empresas como CocaCola, Nike, e outras que conseguem manter seu porte e a fidelidade dos clientes por gerações. 


\subsection{Os 4 Rs}

Os 4 Rs são quatro palavras com as iniciais em R, onde cada uma delas traz um benefício capaz de criar valor para os clientes. Pavoni et al. (2009) explicam que os R's fazem referência ao relacionamento, retenção, referência e recuperação.

Segundo Claro (2006, p. 10, grifo nosso), retenção é uma maneira de manter os clientes por meio de atitudes diferenciadas, nas quais suas expectativas não sejam apenas supridas, mas superadas. Pavoni et al. (2009, p. 4) ainda completa: "Para que isso ocorra a empresa e seus funcionários devem estar comprometidos com esse propósito, para que o seu cliente se sinta especial e perceba a importância dele para a empresa". A retenção está diretamente ligada ao próximo $\mathrm{R}$, o relacionamento. Essa sequência de experiências positivas faz com que a barreira consumidor/vendedor seja quebrada e uma relação afetuosa tome o seu lugar.

Segundo Pavoni et al. (2009, grifo nosso), relacionamento ocorre quando um cliente é fidelizado devido o atendimento que recebeu na empresa e continua satisfeito, mesmo a longo prazo. Essa sensação de sentir-se parte da empresa, e não apenas um consumidor comum, acaba gerando uma alta carga de satisfação no cliente, fazendo com que este se torne uma referência para novos clientes.

Barnes (2002, grifo nosso) sugere que referência é o cliente satisfeito com os serviços e/ou produtos da empresa e o poderoso efeito de propagação que essa satisfação causou no mesmo, ou seja, esse cliente foi atendido de forma tão satisfatória que compartilhou sua experiência com conhecidos, fazendo com que esses também se tornem clientes da empresa bem qualificada. O bom atendimento numa empresa funciona como um combustível para o sucesso comercial, se a equipe não possui técnicas de abordagem eficiente, o estabelecimento sentirá os impactos e a maneira mais saudável para amenizar os danos, é fazendo uso do quarto R, definido por: recuperar.

Claro (2006, p. 10, grifo nosso) explica que recuperar é, basicamente, realizar atividades de recuperação de clientes perdidos em virtude de alguma insatisfação. Pavoni et al. (2009, p. 4) completam, dizendo que "[...] a mesma deve mostrar a importância que ele tem dentro do contexto da organização e tentar recuperar a sua lealdade. Isso também mostrará para o cliente que a empresa está comprometida com a sua satisfação". A concorrência no mercado é colossal, um atendimento diferenciado e uma abordagem que supere as expectativas do cliente são ações importantes para se destacar perante os demais. 
A implementação de um software que siga de forma eficiente o modelo de MR desejado pelo cliente, unido a uma rede social poderosa e ao modelo dos 4 Rs, torna o marketing da empresa muito mais efetivo.

\subsection{Metodologia IDIP}

A metodologia IDIP é uma ferramenta de CRM (Customer Relationship Management), esta ferramenta visa prestar um atendimento personalizado para o cliente. Segundo Peppers e Rogers (2001), essa metodologia tem sua sigla formada com a primeira letra de cada uma das seguinte palavras: IDENTIFICAR; DIFERENCIAR; INTERAGIR; PERSONALIZAR.

Peppers e Rogers (2001, grifo nosso) explicam esses quatro pontos de forma muito clara, onde identificar se refere a manter um relacionamento agradável com o cliente, tendo conhecimento amplo a respeito do cliente e o conhecendo verdadeiramente, para, assim, poder fazer uso de um atendimento personalizado. Eles ainda complementam, falando que não é possível ter uma relação com alguém que não somos capazes de identificar. Diferenciar é o ato de tratar cada cliente de forma diferenciada. Esse tipo de abordagem ajuda a empresa a classificar estes clientes como tendo um valor elevado - no caso, clientes fiéis, que geram maior lucro para empresa - os clientes que possuem maior potencial - tem um potencial de compra grande, mas a empresa não os aproveita da forma devida - e os clientes classificados como abaixo de zero - onde o valor de compra desses não compensa o custo causado à empresa. Interagir está relacionado à comunicação com o cliente, onde a empresa deve obter informações a respeito deste, visando conhecê-lo melhor para, assim, prestar atendimento e produtos personalizados. E personalizar é o processo final, no qual após conhecer mais a fundo o cliente, a empresa é capaz de beneficiá-lo de maneira individual, ou seja, o processo de compra com a empresa se tornará uma experiência exclusiva e muito especial.

Esses quatro pontos ajudam a conhecer a clientela e a classificá-la, dos mais rentáveis aos menos rentáveis. Essa abordagem é necessária para atendimentos mais personalizados e será muito útil para pôr em prática o próximo método de fidelização: os programas de fidelização de clientes.

\subsection{Programas de Fidelização de Clientes}

Segundo Furlong (1994 apud SILVA, 2001) os programas de fidelização devem ser voltados para fidelizar os melhores clientes da empresa, que no conceito da filosofia de Pareto, a relação 80/20. Esse conceito pode ser entendido como um "programa de fidelização com base na customização no 
atendimento, traduzida como: $80 \%$ de seus negócios vêm de $20 \%$ de seus clientes" (FURLONG, 1994 apud SILVA, 2001, p. 75). Nesse sentido, está a importância do uso do método IDIP, mais especificamente no diferenciar. Para a criação de um programa de fidelização consistente e efetivo, é de extrema importância identificar e conhecer a fundo os clientes de valor elevado, pois será para esses clientes, os que geram maior lucro para empresa, que o programa de fidelização deverá ser priorizado.

Segundo Kotler (2000), essas são as alternativas que mais se destacam:

- Oferecer mais serviços e estes com melhor qualidade - o atendimento ao cliente deve ser feito de forma mais plena possível.

- Benefícios Financeiros - incentivar maior frequência de comprar através de um programa de acúmulo de pontos que podem ser trocados por produtos específicos.

- Benefícios Estruturais - ofertar serviços ou produtos especiais para os clientes mais rentáveis da empresa.

Dentre as ferramentas estudadas, foi desenvolvido um quadro comparativo entre elas com o objetivo de realizar uma análise entre os elementos comuns que as compõem bem como sua estratégia de comunicação (Quadro 1).

Quadro 1 - Quadro comparativo das estratégias.

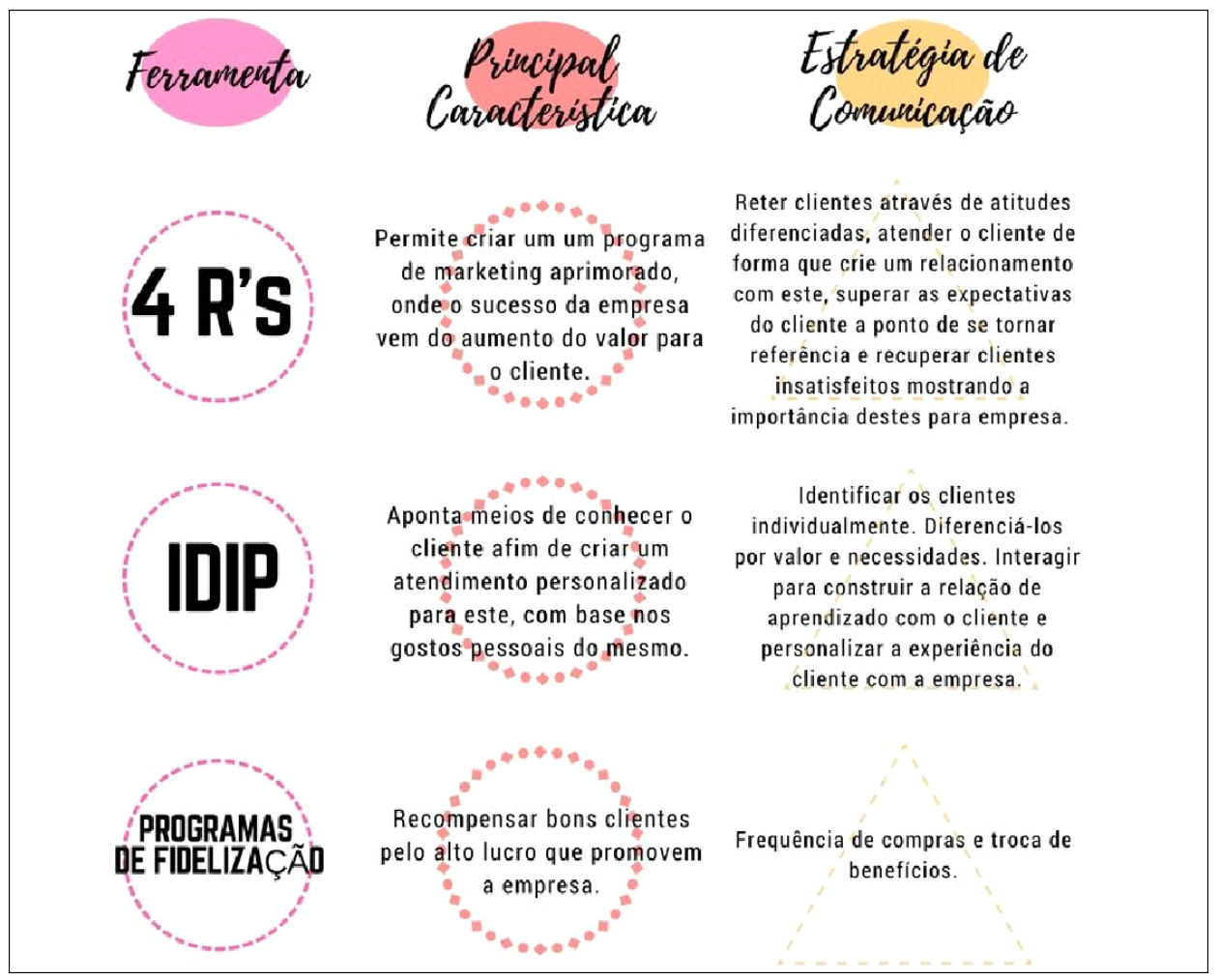

Fonte: elaborado pelos autores a partir do referencial teórico. 


\section{ESTUDO DE CASO}

A empresa deste estudo atua no ramo do vareja de moda, especificamente no segmento de underwear e streetwear. Fundada em 2008, fica localizada na cidade de Meleiro em Santa Catarina. A loja é dirigida por uma única sócia, responsável pelas compras da loja, administração e também atua no atendimento aos clientes, junto a mais dois funcionários, um responsável pelo caixa e outro pelo atendimento, da sua clientela em geral, 92\% das clientes são mulheres. Ao longo dos anos, a demanda de clientes sugeriu a venda de roupas e ampliou-se, tanto o nicho de mercado quanto sua estrutura física.

\subsection{Coleta e Análise de Dados}

Para medir a fidelidade dos clientes da empresa, foi necessário ter acesso ao sistema da mesma e analisar o cadastro de cada cliente minuciosamente. Com base nos dados fornecidos pela empresa estudada, foi analisada a frequência de compras dos clientes cadastrados. $O$ primeiro passo foi obter o número total de clientes, depois, estas foram divididas pela sua frequência de compra na loja.

Após a coleta no sistema da empresa, pode ser encontrado o cadastro de 1311 clientes. Destas, 301 estão inativas há mais de 5 anos, 206 há mais de 3 anos. Pode-se inferir que, devido ao longo tempo sem atividade na empresa, essas clientes são consideradas inativas. Ainda, 713 clientes compraram no último ano e 91 compraram no último mês. Bonel (2012), através de dados fornecidos pelo Procon-FGV, pontua os motivos mais frequentes da perda de clientes (Figura 2):

Figura 2 - Motivos mais frequentes da perda de clientes.

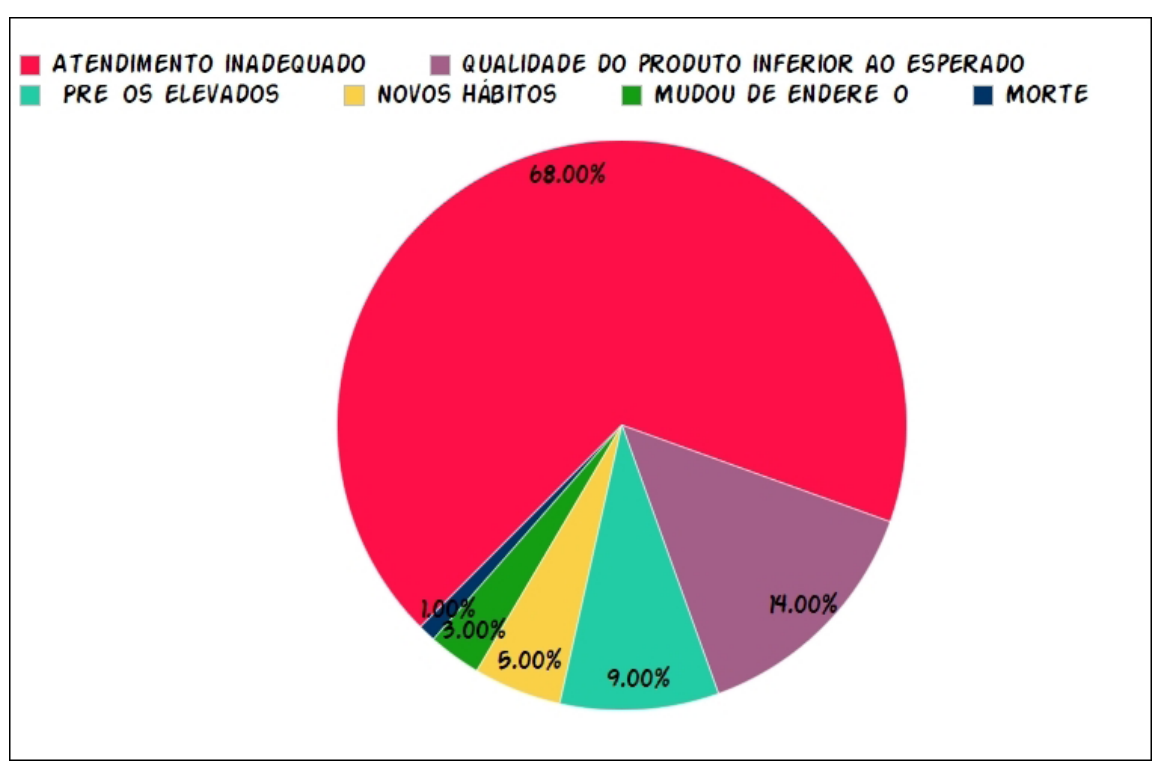

Fonte: elaborado pelos autores segundo referencial teórico.

Projética, Londrina, v.10, n.3, p. 143-158, jul./dez. 2019 
Após observar essas informações, surgiu a curiosidade de analisar os dados das clientes juntamente com a proprietária da empresa para entender os motivos desta possuir 507 clientes inativos. Por se tratar de uma cidade de 7 mil habitantes, sendo apenas pouco mais de 3 mil no centro da cidade (IBGE, 2010), o processo de identificação de clientes inativos há tanto tempo se tornou mais fácil pelo fato de a sócia conhecer pelo nome cada uma das suas clientes.

Buscou-se analisar quais clientes haviam mudado de endereço ou falecido. Das 507 clientes inativas, 8 faleceram e 203 clientes mudaram de endereço (cidade). Como citado anteriormente, das 507 clientes inativas, foi possível identificar o motivo da inatividade de 211 delas. Porém, 296 clientes inativas ainda não tiveram seus motivos identificados. Foi sugerido à proprietária que fizesse uso da recuperação, mencionada na ferramenta 4 Rs, para tentar recuperar a lealdade desses clientes.

Com base nos dados do último ano, a loja possui cerca de 804 clientes ativas. Segundo Furlong (1994 apud SILVA, 2001) sugere, 80\% do faturamento de uma empresa vem de $20 \%$ de seus clientes. Seguindo essa métrica, podese afirmar que pouco mais de 160 clientes são responsáveis por $80 \%$ do faturamento do estabelecimento, e é para essas 160 clientes especiais que a empresa poderá criar os programas de fidelização, como forma de recompensar os lucros obtidos a partir destas.

\subsection{Convergência dos Modelos}

Por meio da interpretação de cada modelo, buscou-se uma palavrachave que identificasse cada um. Essa análise resultou em algumas palavras em comum que foram relacionadas na última coluna, conforme a figura (Figura 3).

Figura 3 - Convergência de modelos.

\section{Modelo Conceito Conceitos em Comum Convergência dos Modelos}

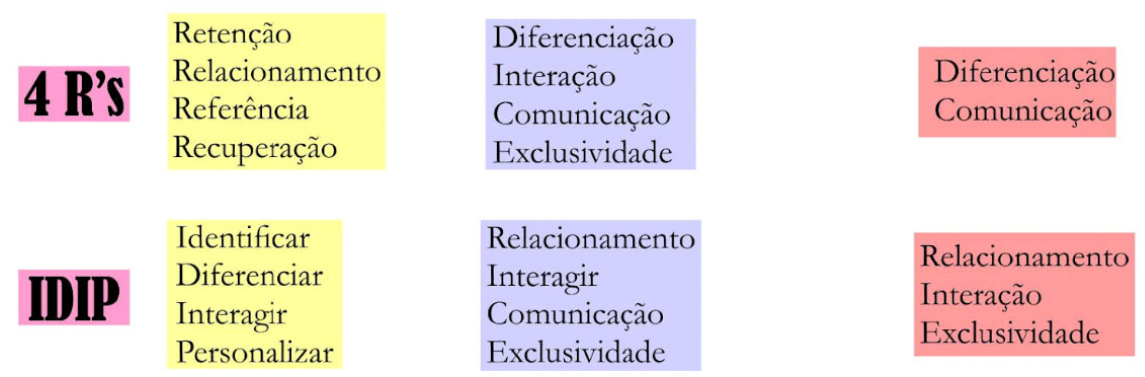

Fonte: Elaborado pelos autores segundo referencial teórico. 
A partir desse modelo proposto, utilizou-se como base para analisar os dados coletados, como sugere a figura 4.

Figura 4 - Análise dos dados coletados.

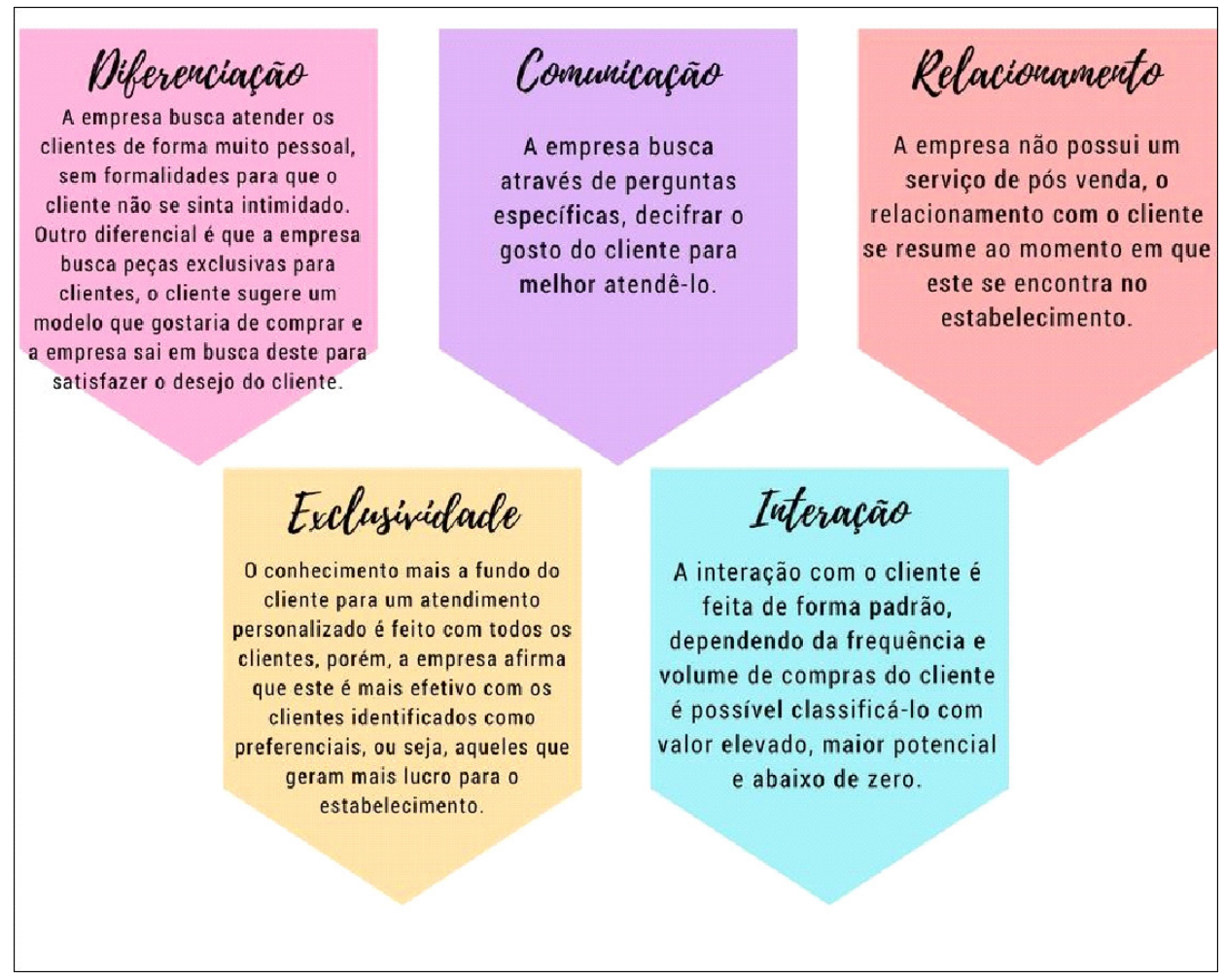

Fonte: Elaborado pelos autores segundo referencial teórico.

A análise expôs uma série de fatores a serem melhorados na empresa e alguns pontos a serem mantidos ou aprimorados. O campo Diferenciação (grifo nosso) foi considerado muito satisfatório. A empresa fornece um serviço de busca de encomendas inovador para região. O campo Comunicação foi considerado satisfatório, segundo a empresa, os atendentes fazem uma série de perguntas durante o atendimento visando a um melhor atendimento. Além disso, os funcionários buscam evitar palavras muito formais durante o atendimento, para fazer com o que o cliente sinta-se mais à vontade no estabelecimento. O campo Relacionamento foi considerado muito insatisfatório. A empresa não realiza qualquer serviço de pós-venda. Sugere-se que a mesma busque treinamento para otimizar esse ponto falho do atendimento. Para se criar um relacionamento real com o cliente, este deve ser mantido, também, no pósvenda, que é onde o cliente irá perceber que a loja não o trata de forma especial apenas no estabelecimento. Quando o produto já foi vendido, a empresa imaginava que não precisaria mais manter contato com o cliente após a compra, porém apenas uma ligação questionando a satisfação com o produto adquirido já seria o suficiente para surpreendê-lo de forma positiva. O campo Interação foi considerado satisfatório. A interação com os clientes é feita de forma satisfatória e a empresa se diz capaz de identificar quais clientes proporcionaram maior lucro para empresa analisando o histórico de compras de cada um deles. Por fim, o campo Exclusividade foi considerado regular. A empresa busca decifrar 
as preferências do cliente através de perguntas específicas para efetuar um atendimento personalizado com este, porém, alega-se que é muito difícil decifrar todos os gostos de um freguês em 15 minutos de atendimento. Por esse motivo, o atendimento personalizado realmente efetivo acontece apenas com os clientes que visitam a loja com mais frequência. O programa de fidelização não foi utilizado por não apresentar suporte teórico relevante. Tal modelo pode ser utilizado como complemento dos demais.

\section{METODOLOGIA}

O enquadramento metodológico pode ser classificado quanto à abordagem do problema, quanto aos objetivos e quanto aos procedimentos.

$\mathrm{Na}$ abordagem do problema, foi utilizada a pesquisa qualitativa, conforme Beuren (2004, p. 92) destaca que na pesquisa qualitativa "[...] concebem-se análises mais profundas em relação ao fenômeno que está sendo estudado, [...] visa destacar características não observadas por meio de um estudo quantitativo, haja vista a superficialidade deste último". Assim, optouse por este tipo de pesquisa porque o objeto de análise são construções sociais que se modificam a todo o tempo. Sendo o marketing de relacionamento o objeto da presente pesquisa, ele pertence a um contexto social, pois se constitui na relação entre clientes e empresa.

Referente aos objetivos, este estudo é de caráter exploratório. Raupp e Beuren (2006, p. 81) frisam que "explorar um assunto significa reunir mais conhecimento e incorporar características inéditas, bem como buscar novas dimensões até então não conhecidas". Dessa forma, busca-se uma aproximação com a realidade pesquisada no intuito de torná-la explícita e buscar uma familiaridade, ou seja, um conhecimento mais profundo sobre o objeto social pesquisado.

Quanto aos procedimentos, classifica-se como pesquisa bibliográfica e estudo de caso. No que se refere à pesquisa bibliográfica, utilizaram-se obras de diversos autores como fonte de informações para a fundamentação do assunto abordado e confronto com o caso estudado. Cervo e Bervian (2002, p. 65) enfatizam que:

A pesquisa bibliográfica procura explicar um problema a partir de referências teóricas publicadas em documentos. Pode ser realizada independentemente ou como parte da pesquisa descritiva ou experimental. Em ambos os casos, busca conhecer e analisar as contribuições culturais ou científicas do passado existentes sobre um determinado assunto, tema ou problema. 
A metodologia de estudo de caso é utilizada para unir a teoria à prática. De acordo com Martins e Lintz (2007, p. 23) o estudo de caso é conceituado como:

[...] uma técnica de pesquisa cujo objetivo é o estudo de uma unidade que se analisa profunda e intensamente. Considera a unidade social estudada em sua totalidade, seja um indivíduo, uma família, uma instituição, uma empresa, ou uma comunidade, com o objetivo de compreendê-los em seus próprios termos. É uma investigação empírica que pesquisa fenômenos dentro do seu contexto real. O estudo reúne o maior número de informações detalhadas, por meio de diferentes técnicas de coleta de dados.

Desse modo, o estudo é qualitativo, exploratório e realizado mediante pesquisa bibliográfica com a aplicação de estudo de caso. Os dados foram produzidos a partir de uma entrevista não estruturada com a proprietária e através do banco de dados cadastrais de clientes da empresa pesquisada. O sistema utilizado na loja permite acessar a quantidade total de clientes e a frequência de compras desses. O sistema ainda permite verificar há quanto tempo o cliente não efetua compras na empresa, podendo assim ser analisada sua taxa de fidelidade com mais precisão e rapidez.

\section{CONSIDERAC̣ÕES FINAIS}

O relacionamento entre empresa e clientes é debate constante no mundo dos negócios. A preocupação constante com o aumento massante da concorrência, reforça a necessidade da retenção, manutenção e fidelização da clientela. Empresas sérias e que buscam resultados efetivos, seja no quesito vendas ou na referência que a empresa representa no seu meio, devem estar totalmente voltadas para os clientes, caso contrário, estarão fadadas ao declínio.

O objetivo principal do trabalho foi pesquisar ferramentas de gerenciamento de relacionamento de clientes, de forma que pudessem ser aplicadas em uma empresa de varejo de moda. Ao longo da pesquisa, as ferramentas mais interessantes encontradas foram os 4 Rs, a metodologia IDIPe os programas de fidelização de clientes. Pelo fato dessas ferramentas atenderem parcialmente uma loja de moda, foi criado um modelo de convergência a fim de buscar o melhor de cada estratégia, para então, serem implementados em uma empresa do varejo de moda. Foi sugerido utilizar um dos pontos dos 4 Rs, mais especificamente "recuperação", para tentar recuperar a lealdade das clientes inativas. 
As vantagens do marketing de relacionamento foram abordadas com base nos autores citados e infere-se que o MR é o que diferencia uma empresa das outras e coloca a ênfase do desenvolvimento dos processos de vendas na abordagem e na personalização da venda. É, portanto, um processo qualitativo que tem seu custo diluído no tempo em que o cliente desenvolverá negócios com a empresa na busca de benefícios mútuos.

Deste modo, pode-se afirmar que o objetivo geral foi atingido com êxito, pois foram apresentadas várias ferramentas de gerenciamento de relacionamento de clientes que podem ser aplicadas no varejo de moda, além de sua importância e vantagens. Sugere-se como trabalhos futuros aplicar o modelo de convergência com o desenvolvimento de indicadores quantitativos para que se possa comparar um estudo de caso com outros casos, inclusive em modelos de negócios virtuais.

\section{REFERÊNCIAS}

BAKER, Michael J. Administração de marketing. 5. ed. Rio de Janeiro: Campus, 2005.

BARKI, Edgard; BOTELHO, Delane; PARENTE, Juracy. Varejo: desafios e oportunidades em mercados emergentes. Revista de Administração de Empresas, São Paulo, SP, v. 53, n. 6, p. 534-538, nov./dez. 2013.

BARNES, James $\mathrm{G}$. Segredos da gestão pelo relacionamento com os clientes CRM. Rio de Janeiro: Qualitymark, 2002.

BEUREN, Ilse Maria. Como elaborar trabalhos monográficos em contabilidade: teoria e prática. 2. ed. São Paulo: Atlas, 2004.

BONEL, Claudio. Por que perdemos clientes? 2012. Disponível em: http:// www.administradores.com.br/artigos/negocios/por-que-perdemosclientes/65668/. Acesso em: 16 abr. 2018.

BRAGA, Antônio. Quanto custa a perda de clientes? 2014. Disponível em: http://bonnaconsultores.com.br/quanto-custa-a-perda-de-clientes/. Acesso em: 14 abr. 2018.

CERVO, Amado Luiz; BERVIAN, Pedro Alcino. Metodologia científica. 5. ed. São Paulo: Prentice Hall, 2002.

CLARO, Danny Pimentel. Marketing de relacionamento: conceitos e desafios para o sucesso do negócio. 2006. Disponível em: https://www. researchgate.net/profile/Danny_Claro/publication/5104849_Marketing_ de_relacionamento_Conceitos_e_Desafios_para_o_Sucesso_do_Negocio/ links/02e7e52c585a882077000000/Marketing-de-relacionamentoConceitos-e-Desafios-para-o-Sucesso-do-Negocio.pdf. Acesso em: 4 maio 2018. 
COLTRO, Alex. Os novos modelos de administração na era da competitividade. 2002. Disponível em: http://www.convibra.com.br/upload/paper/adm/ adm_3009.pdf. Acesso em: 1 abr. 2018.

CZINKOTA, Michael R.; MONTINGELLI JUNIOR, Nilvaldo. Marketing as melhores práticas. Porto Alegre: Bookman, 2001.

ENGEL, Elenice Padoin Juliani; BÚRIGO, Lúcia Andréa; PEREIRA, Luciane de Carvalho. Marketing de relacionamento. Criciúma: Ediunesc, 2015.

GORDON, lan; PINHEIRO, Mauro. Marketing de relacionamento: estratégias, técnicas e tecnologias para conquistar clientes e mantê-los para sempre. São Paulo: Futura, 2001.

IBGE. Censo Demográfico 2010: características gerais da população.2010. Disponível em: https://cidades.ibge.gov.br/brasil/sc/meleiro. Acesso em: 2 maio 2018.

KOTLER, Philip. Administração de marketing. São Paulo: Prentice Hall, 2000.

KOTLER, Philip. Marketing essencial: conceitos, estratégias e casos. 2. ed. São Paulo: Prentice Hall, 2005.

KOTLER, Philip; ARMSTRONG, Gary. Princípios de marketing. 15. ed. São Paulo: Person Educacional do Brasil, 2015.

KOTLER, Philip; ARMSTRONG, Gary. Princípios de marketing. 9. ed. São Paulo: Prentice Hall, 2003.

MARTINS, Gilberto de Andrade; LINTZ, Alexandre. Guia para elaboração de Monografias e Trabalho de Conclusão de Curso. 2. ed. São Paulo: Atlas, 2007.

PAVONI, Graziele Ferracioli; ROCHA, Quézia Cristina; VENDRAME, Francisco César; SARRACENI, Jovira Maria; VENDRAME, Máris de Cássia Ribeiro. Marketing de relacionamento. 2009. Disponível em: http://www.unisalesiano. edu.br/encontro2009/trabalho/aceitos/CC33208122896.pdf. Acesso em: 23 abr. 2018.

PEPPERS, Don; ROGERS, Martha. CRM series: marketing 1 to 1. 2. ed. São Paulo: Makron Books, 2001. Disponível em: http://fejemg.org.br/ plataformadainformacao/wp-content/uploads/2015/09/Marketing-1-to-1.pdf. Acesso em: 20 abr. 2018.

PINHO, José Benedito. Comunicação em marketing. 9. ed. São Paulo: Papirus, 2008.

RAUPP, Fabiano Maury; BEUREN, Ilse Maria. Como elaborar trabalhos monográficos em contabilidade: teoria e prática. 3. ed. São Paulo: Atlas, 2006.

SILVA, Paulo Cezar Ribeiro da. A customização no atendimento como fator de fidelização do cliente às lojas de decoração de alto estilo. 2001. Dissertação (Mestrado em Gestão Empresarial) - Fundação Getúlio Vargas, Rio de Janeiro, 2001. Disponível em: https://bibliotecadigital.fgv.br/dspace/bitstream/ handle/10438/3747/Paulo-C.-R.-da-Silva. pdf?sequence=1\&isAllowed=y. Acesso em: 13 abr. 2018. 
SIQUEIRA, Antônio Carlos Barrosa da. Marketing empresarial, industrial e de serviços. São Paulo: Saraiva, 2005.

SOUZA, Alexandre Alves de. Satisfação, lealdade, fidelização e retenção de clientes. 2009. Disponível em: http://files.blogdocallcenter.com/200001703eacbeebc58/Estudo_T8_0183_0579_excelenciaemgestao.org.pdf. Acesso em: 13 abr. 2018.

VAVRA, Terry G. Marketing de relacionamento (aftermarketing): como usar o debase marketing para a retenção de clientes ou consumidores e obter a recompra continuada de seus produtos ou serviços. São Paulo: Ed. Atlas, 1993.

VIEIRA, Vanessa Veiga. Estratégia de co-branding para o mercado pme. Lajeado, RS: UNIVATES, 2015. Disponível em: https://www.univates.br/ editora-univates/media/publicacoes/167/pdf_167.pdf. Acesso em: 13 abr. 2018. 